\title{
Sexually transmitted disease in antenatal patients
}

\author{
R. N. T. THIN AND A. M. MICHAEL \\ Royal Herbert Hospital, Woolwich
}

DURING pregnancy most women regard a vaginal discharge as a normal event and rarely complain about it. Thus less than 1 per cent. of women attending the authors' clinic complain of a discharge yet a third admit to this symptom on direct questioning, and a few suffer severe discomfort. Other workers, such as Purola, Jahkola, and Österlund (1967), have made similar observations. The discharge may indicate infection, and during parturition organisms in the lower genital tract may invade the infant and cause neonatal infection. The purpose of this paper is to present the results of a small prospective study of antenatal patients for the presence of such organisms, many of which may have been transmitted to the mother during sexual intercourse.

\section{Methods}

During the period of the study all women seen at the antenatal clinic in the 36th week of their pregnancy (a total of 56) were examined for clinical evidence of syphilis, gonorrhoea, and other conditions, including scabies, pediculosis, genital herpes, and genital warts.

Blood was taken for the cardiolipin Wassermann reaction (CWR), the Venereal Disease Research Laboratory (VDRL), and the Reiter protein complement-fixation (RPCF) tests. Smears were collected from the urethra and cervix for fluorescent antibody staining for Neisseria gonorrhoeae and Giemsa staining for Chlamydia oculogenitale inclusions. A third cervical smear was also stained by Gram's method and examined for pus cells and Gramnegative intracellular diplococci. A smear for Gramstaining was taken from the vagina and examined for fungal elements and trichomonads. A swab of secretion was collected from the posterior fornix of the vagina and immediately placed in Stuart's transport medium. Within a few hours a wet preparation from this specimen was examined for Trichomonas vaginalis. Cultures were made on heated blood agar, blood agar, and Sabouraud's medium for $N$. gonorrhoeae, Haemophilus vaginalis, and Candida albicans, and material was inoculated into Feinberg-Whittington or Squires-McFadzean trichomonas culture medium. A 'first catch' urine specimen was similarly examined for the presence of pus, bacteria, candida, and trichomonads.

Smears for gonococcal fluorescent staining were prepared and examined as described by Thin (1970). Smears for chlamydia inclusions were fixed in acetone for 3 minutes and stained with Giemsa stain, using the method described by Lynch, Raphael, Mellor, Spare, Hills, and Inwood (1963). They were scanned using a $\times 10$ objective and suspicious cells were studied using a $\times 100$ objective. Each slide was examined for at least $\mathbf{3 0}$ minutes.

Agar culture plates and Sabouraud slopes were examined after 48 hours and trichomonas media after 24, 48 and 72 hours' incubation at $36^{\circ} \mathrm{C}$.

\section{Results}

Of the 56 patients studied, none showed clinical signs of syphilis, gonorrhoea, scabies, pediculosis, genital herpes, cr genital warts.

Investigations did not reveal that any patient was suffering from latent syphilis or gonorrhoea. Forty patients had candidosis, five had trichomoniasis and $H$. vaginalis was found in four (Table). Trichomonads were found in two patients by smear and culture, in two by culture alone, and in one by wet smear alone.

\section{T A B L E Findings in 56 antenatal patients}

\begin{tabular}{lcc}
\hline Condition & No. & Per cent. \\
\cline { 3 - 4 } \cline { 3 - 3 } Syphilis & 0 & 0 \\
Gonorrhoea & 0 & 0 \\
Candidosis & 40 & $71 \cdot 4$ \\
Trichomoniasis & 5 & $8 \cdot 9$ \\
H. vaginalis & 4 & $7 \cdot 1$ \\
\hline
\end{tabular}

Twelve patients had ten or more pus cells per high power microscope field in their cervical smears, six had urinary infections due to Escherichia coli, and five had pyuria, but no organisms could be isolated.

\section{Discussion}

The incidence of fresh cases of early syphilis in the region where this study was carried out is about 1 per 100,000 women (British Co-operative Clinical Group, 1968a), so it is not surprising that the results of all serological tests for syphilis were negative. Recent studies, reviewed by Mora (1969), show that fluorescent treponemal antibody tests become positive earlier in the course of the disease than other tests. It is 
suggested that one of these procedures should be included among the tests carried out on each specimen of blood taken from every expectant mother.

The local incidence of fresh cases of gonorrhoea is about 1 per 15,000 women (British Co-operative Clinical Group, 1968b), so that gonorrhoea would have been a chance finding in such a small series. Few systematic investigations into the incidence of gonorrhoea in antenatal patients have been published, but Purola and others (1967) found the infection in 0.45 per cent. of 1,335 gravid women studied at Helsinki in Finland. Gaal, Rich, and Hansman (1968) found no case of gonorrhoea in 200 expectant mothers studied in Sydney, Australia, and concluded that it appeared so rarely in these women that the collection of urethral and cervical swabs from every patient was impractical. But because gonorrhoea is readily treated in many parts of the world and because failure to treat it may be so unfortunate both for the infant and for the mother, it is considered that investigation of all gravid women is important. Fluorescent antibody techniques form a useful screening method which is both sensitive and specific. Purola and others (1967) used this technique but took only urethral smears. The authors recommend that cervical smears should also be taken since they give a greater yield of positive results, but for a patient in whose case the cervix cannot be seen, a vaginal smear is a useful alternative, as shown by Thin (1970).

Fungal elements were found in 71.4 per cent. of the patients. It is well known that candidosis is common in pregnancy and a similar incidence has been quoted by other workers. Many of these women show no clinical abnormality and it is common practice to treat only those who have clinical vaginitis. Hurley and Morris (1964) have pointed out that only seven of the thirty species of Candida are pathogenic to man. Where facilities exist, identification of the candida species will therefore assist the clinician in determining which patients require treatment. Identification appears to be important, because a pathogenic species which is causing little or no clinical disease in the mother, may invade the infant during parturition and produce neonatal thrush.

Trichomonads were found in 8.9 per cent. of the women. Contrary to the findings of Cree (1968), the parasite proved to be extremely difficult to identify in Gram-stained smears and the findings by that method are not included. However, culture was a valuable addition to the wet smear as a means of finding this organism. The incidence of trichomoniasis in sexually-active women lies between 3.4 and 25 per cent. or higher, according to King (1964a). There appear to be few published accounts of its incidence in antenatal patients. Debiasi (1939), writing from
Italy, had diagnosed the condition in 15.1 per cent. of 1,000 gravid women, and Purola and others (1967) found it in 7.2 per cent. of their series. Thus, though the increased acidity of the vaginal secretion during pregnancy might be expected to lower the incidence of trichomoniasis, the condition is found in a considerable number of antenatal patients. Routine investigation is worth while, as neglect may lead to the development of painful vulvo-vaginitis. Metronidazole usually eliminates the parasite and does not appear to harm mother or foetus (Scott Gray, 1964; Gray and Barnes, 1965), although it is prudent to withhold treatment during the first trimester.

$H$. vaginalis was found in four women. King (1964b) commented that evidence concerning the pathogenicity of this organism in females was conflicting, and recent work has not clarified the problem. The numbers here are too small to draw any conclusions, but it is worth commenting that two of these women had cervicitis.

No pathogens were found in four women with cervicitis or in two with pyuria. These conditions could have been due to $\mathrm{T}$-strain mycoplasma or chlamydia, for there is much evidence that Giemsa staining is less sensitive than culture or fluorescent antibody techniques in identifying the latter in genital secretions (Dawson and Schachter, 1967).

An attempt was made to examine 'first catch' early morning urine specimens from the husbands of these patients. Some were away from home, and many did not cooperate, and the urines which were received proved to be normal. In a closed community such as that under investigation, this type of inquiry is difficult to pursue.

Dr. C. S. Nicol kindly provided facilities for fluorescent antibody staining at St. Thomas's Hospital in London, and the other investigations were done in a small laboratory a short distance from the clinic. The selection of investigations may be adjusted to suit the requirements of the study and the available facilities. For instance, the authors hope soon to introduce culture for mycoplasmas and the fluorescent treponemal antibody-absorption test. Fresh wet smears and stained smears can be examined in the clinic and treatment can be started at once. Microbiological investigations should be done at the first visit and repeated at the 36th week. In countries with a high incidence of syphilis it is important to take blood for serological testing early in pregnancy and again about the 34th week, especially when sensitive tests are not available. All organisms mentioned in this study, with the possible exception of $H$. vaginalis, are potentially pathogenic for mother and infant, but are readily treated. Careful investigation of all gravid women is considered to be important to detect. 
serious infection and to minimize the discomfort of vaginal discharge.

\section{Summary}

Micro-organisms found in the lower genital tract of pregnant women may have been introduced during sexual intercourse, and may invade the infant during parturition. The authors examined and investigated 56 pregnant patients for the presence of such organisms. None of the women showed evidence of syphilis, gonorrhoea, scabies, pediculosis, genital warts, genital herpes, or Chlamydia oculogenitale infection. Candidosis was found in forty patients, trichomoniasis in five, and Haemophilus vaginalis in four. It is suggested that careful investigation of expectant mothers is very important. The selection of investigations may be varied according to the facilities available and the population concerned.

\section{References}

British Co-operative Clinical Group (1968a). Brit. f. vener. Dis., 44, 307.

- (1968b). Ibid., 44, 299.

CreE, G. E. (1968). Ibid., 44, 226.

Dawson, C. R., and Schachter, J. (1967). Amer. F. Ophthal., 63, 1288.

DeBIASI, E. (1939). Ann. Ostet. Ginec., 61, 281.

GaAi, R., Rich, R., and Hansman, D. (1968). Med. F. Aust., 1, 634.

Gray, L. A., and Barnes, M. L. (1965). Amer. F. Obstet. Gynec., 92, 125.

HuRLEY, R., and MoRris, E. D. (1964). F. Obstet. Gynaec. Brit. Cwlth, 71, 692.
KING, A. (1964a). 'Recent Advances in Venereology', p. 473. Churchill, London. (1964b). Idem, p. 374.

Lynch, M. J., Raphael, S. S., Mellor, L. D., Spare, P. D., Hills, P., and INwood, M. J. H. (1963). 'Medical Laboratory Technology,' p. 257C. Saunders, Philadelphia.

MORA, Z. P. (1969). Brit. F. vener. Dis., 45, 23.

Purola, E., Jahkola, M., and Österlund, K. (1967). Ann. Chir. Gynaec. Fenn., 56, 95.

Scott-Gray, M. (1964). f. Obstet. Gynaec. Brit. Cwlth, 71, 82.

ThIN, R. N. T. (1970). Brit. f. vener. Dis., 46, 27.

Maladies transmises sexuellement dans un groupe de malades d'une consultation prenatale

SOMMAIRE

Les micro-organismes trouvés dans les voies génitales basses des femmes enceintes peuvent y être parvenus pendant un rapport sexuel et ils peuvent contaminer l'enfant lors de l'accouchement. Les auteurs ont examiné 56 femmes enceintes et recherché la présence de ces organismes. La syphilis, la gonococcie, la gale, la pédiculose, les papillomes génitaux, l'herpès génital ou une infection par Chlamydozoon oculo-genitale, ne put être mis en évidence chez aucune de ces femmes. Une candidose fut trouvée chez $\mathbf{4 0}$ d'entre elles, la trichomonase chez 5, et Haemophilus vaginalis chez quatre. On considère qu'il faut pratiquer un examen très soigneux chez les femmes enceintes. Le choix des recherches à faire peut varier selon l'installation technique dont on dispose et la population envisagée. 